DOI 10. 18307/2018. 0323

(C) 2018 by Journal of Lake Sciences

\title{
洞庭湖三口洪峰流量和水位变异特性分析
}

\author{
孙思瑞 ${ }^{1}$, 谢 平 ${ }^{1,2 * *}$, 赵江艳 ${ }^{1}$, 桑燕芳 $^{3}$, 宁迈进 ${ }^{4}$, 周 慧 ${ }^{4}$ \\ (1: 武汉大学水资源与水电工程科学国家重点实验室,武汉 430072) \\ (2: 国家领土主权与海洋权益协同创新中心,武汉 430072) \\ (3: 中国科学院地理科学与资源研究所陆地水循环与地表过程重点实验室, 北京 100101) \\ (4:湖南省水文水资源勘测局,长沙 410007)
}

\begin{abstract}
摘 要: 近几十年来,受荆江裁弯、葛洲坝工程运用、三峡水库拦蓄调度、洞庭湖治理以及长江上游水土保持措施等因素 的综合影响, 洞庭湖三口 (松滋口、太平口和藕池口) 的水文情势发生了显著变化, 给湖区防洪、水资源、水生态、水环境等 造成一系列影响. 为了深人认识三口洪水发生的复杂变化, 本文采用水文变异诊断系统和 Zivot-Andrews 结构突变单位根 检验方法, 对三口各水文站点的年最大洪峰流量和年最高洪峰水位序列进行变异诊断, 并对其变异特性和变异原因进行 分析. 结果表明, 各站点洪峰流量序列的变异具有较好的一致性; 受分流能力变化和上游来流变化的影响, 三口各站点的 洪峰流量多呈现方向向下的趋势变异; 受到洪道冲刷、流量减小、顶托减弱、洪道上下游落差增大的影响, 三口各站点洪 峰水位在 2004 年均发生方向向下的跳跃变异.
\end{abstract}

关键词: 水文变异;检测与归因;洪峰流量;洞庭湖;长江

\section{Variability in the annual flood peak discharge and water level in three outlets of Lake Dongting}

\author{
SUN Sirui ${ }^{1}$, XIE Ping $^{1,2 * *}$, ZHAO Jiangyan $^{1}$, SANG Yanfang ${ }^{3}$, NING Maijin $^{4} \&$ ZHOU Hui ${ }^{4}$ \\ ( 1: Key Laboratory of Water Resources and Hydropower Engineering Science, Wuhan University, Wuhan 430072, P.R. China) \\ (2: Collaborative Innovation Center for Territorial Sovereignty and Maritime Rights, Wuhan 430072, P.R.China) \\ (3: Key Laboratory of Water Cycle and Related Land Surface Processes, Institute of Geographic Sciences and Natural Re- \\ sources Research, Chinese Academy of Sciences, Beijing 100101, P.R. China) \\ (4: Hydrology and Water Resources Bureau of Hunan Province, Changsha 410007, P.R.China)
}

Abstract: During recent decades, hydrological regimes at the three outlets (i.e., Songzi, Taiping and Ouchi outlets) of Lake Dongting have been greatly changed, which is comprehensively caused by the cutoff works in the Jingiiang River channels, operation of the Gezhou Reservoir, flood storage and operation of the Three Gorges Reservoir (TGR), and soil-water conservation practices in the upper reaches of the Yangtze River Basin. The obviously hydrological variability in the basin would inevitably influence the flood disasters control, water resources management, and protection of water ecology and environment. For investigating the changes and variability in the hydrological process occurred in the basin, in this study we employed the hydrological variability detection system ( composed of namely primary diagnosis, detailed diagnosis and comprehensive diagnosis) and the Zivot-Andrews unit root test method, mainly to identify the changes in the annual maximum peak flood series and annual highest flood level series measured at five stations at the three outlets of Lake Dongting, as well as attributing their physical causes. The diagnosis system includes many methods, by which shortages of a certain method can be overcome and different results of methods can be compared. The Zivot-Andrews unit root test can be used to determine the local trends in a hydrological series. Diagnosis results indicate that the annual maximum peak flood processes at the three outlets consistently show a similar downward trend, which is closely related to the changes in the water-sediment diversion ability and upstream flow changes. A downward jump point in 1968 was detected at

* 国家自然科学基金项目 (91547205,51579181,91647110)和湖南省水利科技项目（湘水科计【2015】13-21) 联合资 助. 2017-06-16 收稿;2017-09-11 收修改稿. 孙思瑞(1993 ), 女, 硕士研究生; E-mail: threesun123@ 163.com.

** 通信作者; E-mail:pxie@whu.edu.cn. 
some stations, and the three outlets cut-off construction can be the reasons. The annual maximum peak flood process at the Kangjiagang station has local trends, and the trend slope was greatly changed before and after the local trend year 1968 . It can be caused by the influence of the three outlets cut-off construction. The annual highest flooding water level series presented a downward jump in 2004, mainly due to the erosion of flood channels, peak flow reduction, jacking function weakened and the increases in the upstream and downstream changes.

Keywords: Hydrological variability; detection and attribution; flood peaks; Lake Dongting; Yangtze River

洞庭湖三口, 即松滋口、太平口和藕池口, 位于长江中游河段的荆江南岸, 是连接荆江与洞庭湖的纽带, 每年分泄长江洪水人洞庭湖, 为减轻荆江河段的洪水压力做出了重要贡献 ${ }^{[1]}$. 近几十年来, 受荆江裁弯、葛 洲坝工程运用、三峡水库拦蓄调度、洞庭湖治理以及长江上游水土保持措施等的综合影响,洞庭湖三口的水 文情势发生了很大变化 ${ }^{[2-4]}$. 三口出现分流人湖的水量和沙量减少、断流时间增长等现象 ${ }^{[5-6]}$, 湖区和三口的 防洪、水资源、水生态和水环境等受到很大影响 ${ }^{[7]}$. 因此, 识别洞庭湖三口洪水变异特性并进行归因分析, 不 仅对三口防洪减灾应对策略制定和水资源利用有指导作用, 对洞庭湖三口综合整治方案和长江中下游防洪 减灾规划制定也具有重要的参考价值.

围绕洞庭湖三口洪水变化和归因分析问题已有许多研究. 郑文燕 ${ }^{[8]}$ 研究了分流分沙变化对荆江典型洪 水位的影响. 陈俭煌等 ${ }^{[9]}$ 讨论了三峡水库蓄水后, 三口洪道洪水位变化趋势及影响因素. 甘明辉等 ${ }^{[10]}$ 通过 构建长江中下游水沙模型, 模拟了长江与洞庭湖区间的洪水过程, 量化了洞庭湖三口水系洪水对各因素变 化的响应. 徐慧娟等 ${ }^{[11]}$ 通过对比分析下荆江裁湾、葛洲坝水利枢纽和三峡水利枢纽等重大水利工程运行前 后洞庭湖水系分流分沙的变化, 阐述了人类活动对洞庭湖水系洪水特性的显著影响. 基于目前研究可以看 出, 洞庭湖三口水文情势已发生了明显变异. 水文变异是指水文序列的分布形式 (和) 分布参数在某个时间 范围内发生了显著变化 ${ }^{[12]}$. 上述研究大多基于不同时段的水文特性对比分析和构建模型对三口洪水的变 化特性进行讨论, 但缺乏对三口洪水变化的整体变异分析和判断, 也没有对变异程度、变异特点及产生原因 等进行深人探讨.

为了解决上述问题, 需要对洞庭湖三口洪水变异规律进行综合检测, 并对各种影响因素进行系统分析. 考虑到洪水具有破坏性特点, 本文选取洪峰流量 和水位作为洪水的代表性指标, 采用水文变异诊 断系统 ${ }^{[12]}$ 并结合 Zivot-Andrews 结构突变单位根 检验方法 $(\mathrm{ZA} \text { 检验 })^{[13-14]}$, 对洞庭湖三口的洪峰流 量和洪峰水位序列进行变异诊断, 并根据诊断结 果进行变异归因分析.

\section{1 数据资料与研究方法}

\section{1 数据资料}

三口洪道由三口 (松滋口、太平口、藕池口) 分 流人洞庭湖的松滋河、虎渡河和藕池河组成,其中 新江口站、沙道观站分别为松滋河进口西支和东 支控制站, 弥陀寺站为虎渡河进口控制站, 康家岗 站和管家铺站分别控制藕池河的西支和东支, 被 称为三口五站 (图 1).

使用的数据资料包括: (1) 湖南省水文水资源 勘测局提供的三口五站和城陵矶站 1956-2014 年的洪水统计资料及同时期三口分流分沙比统计 资料; (2) 长江水利委员会提供的枝城站 19562014 年洪水统计资料和三峡水库 2003-2014 年 人出库流量日值表; (3) 国家气象数据共享网获取

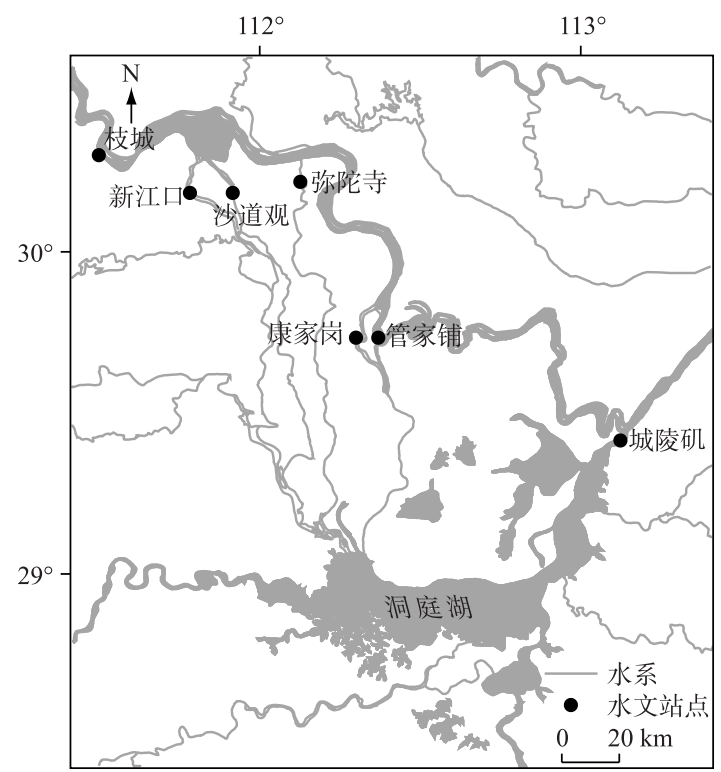

图 1 洞庭湖三口与湖区河系示意图

Fig.1 Three outlets of Lake Dongting and the river network in the basin 
的中国地面气候资料日值数据集 ( V 3.0) 中 1956-2014 年三口附近及长江上游气象站点逐日降雨资料. 上 述资料均经过各单位整编,质量可靠,可保证分析结果的准确性.

\section{2 研究方法}

针对洞庭湖三口洪水变异问题, 本文采用水文变异诊断系统对逐年最大洪峰流量和年最高洪峰水位序 列进行变异识别, 变异形式划分为跳跃和趋势. 对可能存在局部趋势的序列, 借助 ZA 检验进行判断, 并求算 局部趋势节点. 针对变异诊断结果, 采用系统分析法对各因素进行逐一讨论, 以确定变异原因.

1.2.1 分解合成原理 水文序列一般由两种或两种以上成分合成, 假定各成分满足线性叠加特性 ${ }^{[15]}$ (即加法 模型), 可表示为:

$$
X_{t}=Y_{t}+P_{t}+S_{t}
$$

式中, $Y_{t}$ 为确定性的非周期成分 (包括趋势 $C_{t}$ 跳跃 $B_{t}$ 等暂态成分以及近似周期成分等); $P_{t}$ 为确定性的周期 成分; $S_{t}$ 为随机成分 (包括平稳的或非平稳随机成分). 限于有限长度的观测资料, 本文不考虑周期成分.

1.2.2 水文变异诊断系统 由于水文序列 (特别是洪水序列) 变异形式比较复杂, 可能出现单一检验方法结 果可信度差、多种检验方法结果不一致等问题. 欲得到可靠的水文序列变异形式及程度, 需要使用不同统计 方法进行综合分析 ${ }^{[16-17]}$. 本文采用谢平等提出的水文变异诊断系统 ${ }^{[12]}$ 对水文序列进行诊断分析. 该诊断系 统分为 3 个阶段 (图 2): (1) 初步诊断: 定性和定量判断序列是否存在变异并划分变异程 度 $^{[18]}$; (2) 详细诊 断: 利用多种检测方法对跳跃变异和趋势变异情况进行判断分析; (3) 综合诊断: 综合确定最终的变异形式 并输出变异诊断结果. 基于分解合成原理在该诊断系统中添加了多次循环计算, 将扣除跳跃、趋势、局部趋 势等确定性成分后的剩余序列作为新序列再次放人变异诊断系统进行诊断, 直到序列无变异为止. 具体诊 断过程中, 为了合理量化各变异形式的显著性, 取第 1 信度水平 $\alpha=0.05$ 、第 2 信度水平 $\beta=0.01$ 进行假设 检验, 将变异程度分为无、弱、中、强和巨 5 个等级.

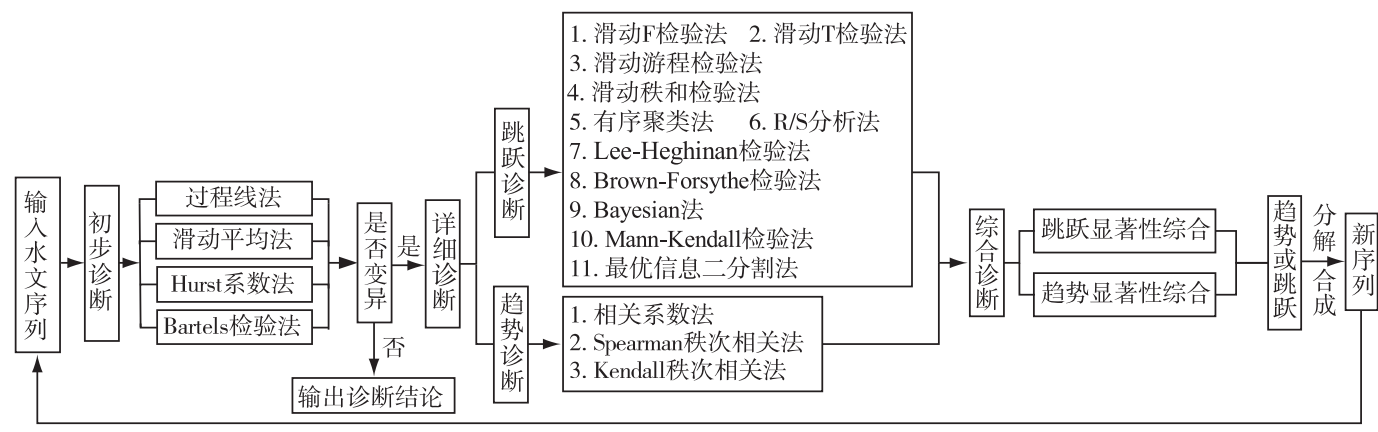

图 2 水文变异诊断系统流程

Fig.2 The flow chart of hydrological variation diagnosis system

1.2.3 Zivot-Andrews 结构突变单位根检验方法 该方法常用来求算时间序列的结构突变点 ${ }^{[19-20]}$. 水文序列 的局部趋势节点即为条件变化产生长期效应的时间节点, 因此 ZA 检验可以用于判断水文序列是否存在局 部趋势并寻找局部趋势节点. ZA 检验的零假设为不包含结构突变的单位根过程, 即 $y_{t}=\mu+y_{t-1}+e_{t}$ 不发生突 变,其中 $t$ 表示时间, $y_{t}$ 表示序列值, $\mu$ 表示对应的截距, $e_{t}$ 表示对应的残差; 备择假设是具有一个未知结构 突变点的趋势平稳 ${ }^{[13]}$, 即 $y_{t}=\mu+y_{t-1}+e_{t}$ 在未知时点发生一次结构突变. 按照截距 (均值) 突变、斜率 (趋势) 突变和截距 (均值) 与斜率 (趋势) 双突变构造模型 $A 、 B 、 C$ :

$$
\begin{gathered}
\text { 模型 } \mathrm{A}: y_{t}=\mu+\alpha \cdot y_{t-1}+\theta \cdot D U_{t}+e_{t} \\
\text { 模型 } \mathrm{B}: y_{t}=\mu+\alpha \cdot y_{t-1}+\gamma \cdot D T_{t}^{*}+e_{t} \\
\text { 模型 } \mathrm{C}: y_{t}=\mu+\alpha \cdot y_{t-1}+\theta \cdot D U_{t}+\beta \cdot t+\gamma \cdot D T_{t}^{*}+e_{t}
\end{gathered}
$$

式中, $\alpha^{i}$ 为检验统计量, 则原假设: 统计量 $\alpha^{i}=1$, 备择假设 $\left|\alpha^{i}\right|<1(i=A 、 B 、 C) ; y_{t}$ 表示序列值. 记 $T_{\mathrm{b}}$ 为局部 趋势节点, $\mu$ 表示截距, $\theta$ 表示截距变化量, $D U_{t}$ 表示 $\theta$ 的系数 $D U_{t}=0\left(t<T_{b}\right), D U_{t}=1\left(t>T_{b}\right) ; \gamma$ 表示计算的斜 
率变化量, $D T_{t}$ 表示 $\gamma$ 的系数 $D T_{t}^{*}=0\left(t<T_{b}\right), D T_{t}^{*}=t-T_{b}\left(t>T_{b}\right), e_{t}$ 表示计算的残差. 记 $T$ 为序列长度,则 $T_{\mathrm{b}}=[2, T-1]$, 记 $\lambda=T_{\mathrm{b}} / T$ 为局部趋势节点在整个样本中的相对位置, 对样本中每个点进行逐一检验, 得到 $a^{i}(i=A 、 B 、 C)$ 的 $t$ 统计量 $t_{a^{\prime}}$ 序列, 记为 $t_{a^{\prime}}(\lambda)$, 从中选择最小值 $t_{a^{*}}^{*}=\min \left\{t_{a^{\prime}}(\lambda)\right\}$, 与相对应的 $t$ 临界值进行比 较, 若 $t_{a^{*}}^{*}$ 大于 $t$ 临界值, 则原假设不成立, 即存在局部趋势节点. 此时, 满足 $t_{a^{*}}^{*}=\min \left\{t_{a^{\prime}}(\lambda)\right\}$ 的 $T_{\mathrm{b}}$ 即为水文 序列的局部趋势节点.

\section{2 洞庭湖三口洪峰变异特性识别}

三口五站年最大洪峰流量、年最高洪峰水位的变化过程如图 3 所示, 各站点年最大洪峰流量序列和年 最高洪峰水位序列的变异诊断结果如表 1 和表 2 所示, 各站点年最大洪峰流量序列变异情况如图 4 所示. 其 中, 康家岗站年最大洪峰流量序列经诊断后发现趋势变异拟合不理想,结合图 4 分析判断,认为存在分段的 局部趋势变异; 取置信度为 0.05 进行 ZA 检验, 结果显示局部趋势显著, 局部趋势节点为 1968 年. 引入变异 幅度和年均趋势变异幅度定量描述各站点序列的变异情况. 流量序列的跳跃变异采用相对变异幅度, 即 $q_{\text {跳 }}=\left(\bar{x}_{\text {后 }}-\bar{x}_{\text {前 }}\right) / \bar{x}_{\text {前. }}$ 水位序列的跳跃变异采用绝对变异幅度, 即 $q_{\text {跳 }}=\bar{x}_{\text {后 }}-\bar{x}_{\text {前. }}$ 考虑到对整体趋势和局部趋势 需参照同一标准, 定义趋势变异幅度为该趋势变化的起始值和终止值之差与整个序列起始值的比值, 即 $q_{\text {趋 }}=\left(\bar{x}_{\text {起 }}-\bar{x}_{\text {址 }}\right) / \bar{x}_{\text {总起 }}$, 年均趋势变异幅度为趋势变异幅度除以该趋势的时间长度 $n$, 即 $q_{\text {年均 }}=q_{\text {道 }} / n$.

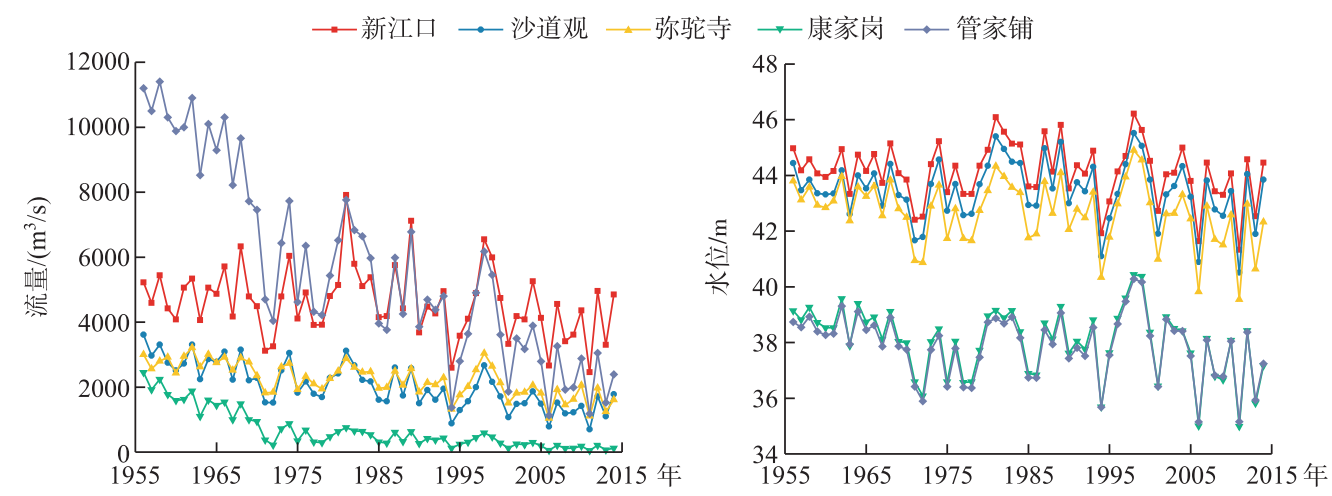

图 3 洞庭湖三口各站点年最大洪峰流量和年最高洪峰水位的变化过程 (1956-2014 年)

Fig.3 Time series of the annual largest flood peak flow and highest flood water level measured at each station in the three outlets of Lake Dongting (1956-2014)

表 1 洞庭湖三口五站年最大洪峰流量序列变异诊断结果 (1956-2014 年)

Tab.1 Detection results of variabilities in the annual maximum peak flood series measured at five stations in the three outlets of Lake Dongting (1956-2014)

\begin{tabular}{ccccc}
\hline \multirow{2}{*}{ 位置 } & 站点 & \multicolumn{3}{c}{ 年最大洪峰流量序列 } \\
\cline { 3 - 5 } & & 初步诊断 & 诊断结论 & 变异幅度 \\
\hline \multirow{2}{*}{ 松滋口 } & 新江口站 & 弱变异 & 跳跃变异 $2000(+) \downarrow$ & $18.20 \%$ \\
& 沙道观站 & 强变异 & 趋势变异 $\downarrow$ & $59.9 \%($ 年均 $1.01 \%)$ \\
太平口 & 弥陀寺站 & 强变异 & 趋势变异 $\downarrow$ & $44.3 \%($ 年均 $0.74 \%)$ \\
藕池口 & 康家岗站 & 强变异 & 分段趋势变异 $(1968) ;$ & $54.7 \%($ 年均 $3.6 \%) ;$ \\
& & & 跳跃变异 $1968(+) \downarrow$ & $21.9 \%($ 年均 $0.5 \%) ; 17.6 \%$ \\
& & 趋势变异 $\downarrow ;$ & $87.2 \%($ 年均 $1.4 \%) ;$ \\
& 管家铺站 & 强变异 & 跳跃变异 $1968(+) \downarrow$ & $11.0 \%$ \\
\hline
\end{tabular}

“+”表示变异显著, “表示变异方向向下;下同. 
表 2 洞庭湖三口五站年最高洪峰水位序列变异诊断结果( 1956-2014 年)

Tab.2 Detection results of variabilities in the annual highest flood water level series measured at five stations in the three outlets of Lake Dongting (1956-2014)

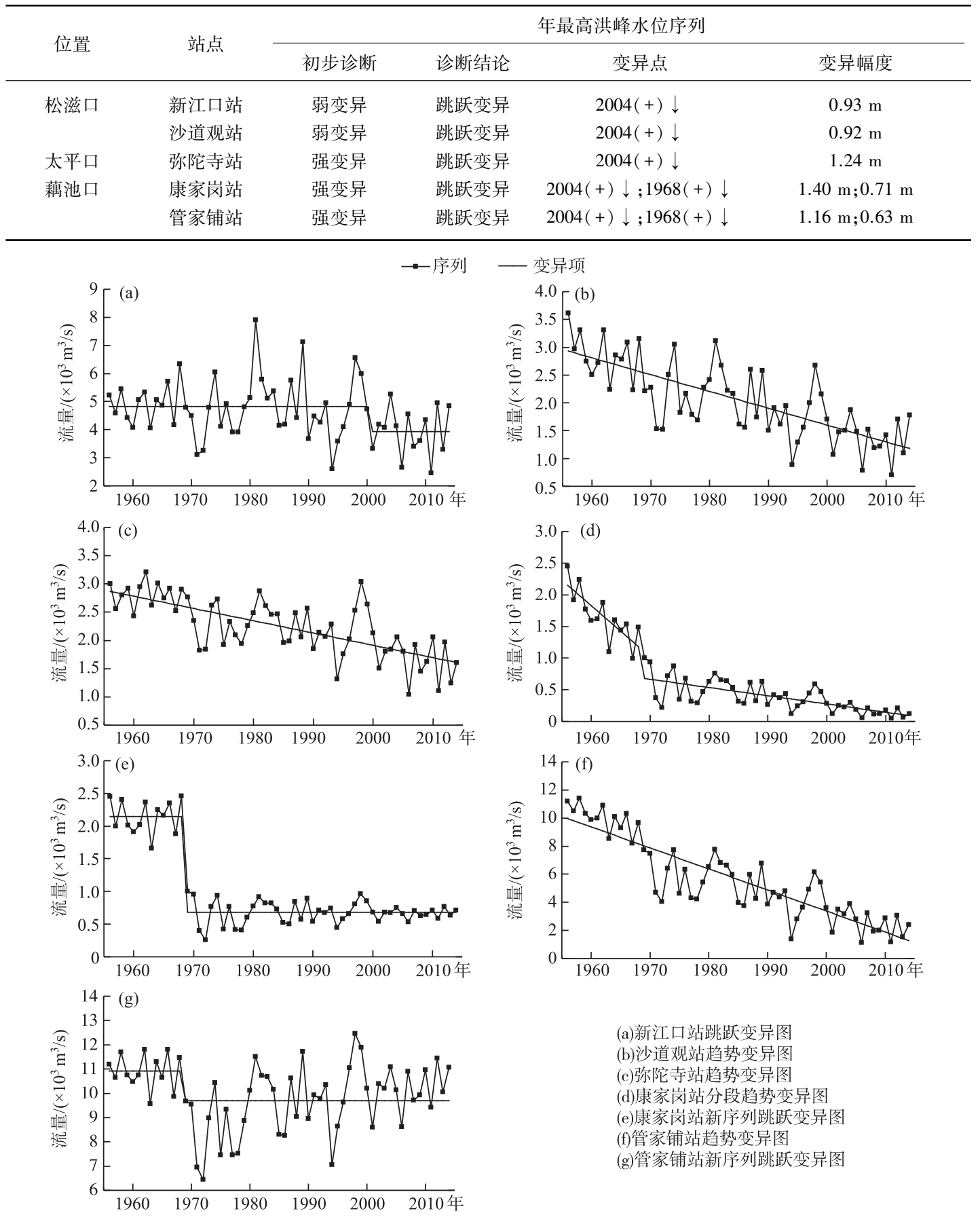

图 4 洞庭湖三口五站年最大洪峰流量变异诊断结果(1956－2014 年)

Fig.4 Abrupt changes detected in the annual maximum peak flood series measured at five stations in the three outlets of Lake Dongting (1956-2014) 
新江口站仅在 2000 年发生方向向下的跳跃弱变异,与其他站点相比其变异程度较弱,变异幅度最小 (表 1 和图 4). 沙道观站和弥陀寺站均发生方向向下的趋势变异. 康家岗站为分段趋势变异,由两段差异较 大的方向向下的趋势组成, 局部趋势节点为 1968 年, 年均下降幅度由 1968 年前的 3.6\% 锐减为 1968 年后的 $0.5 \%$; 分段扣除趋势成分后,新序列在 1968 年发生方向向下的跳跃变异. 管家铺站发生方向向下的趋势变 异, 年均下降幅度在五站点中最大, 扣除趋势成分后, 新序列在 1968 年发生方向向下的跳跃变异. 综上, 三 口五站的年最大洪峰流量序列除新江口站为方向向下的弱跳跃变异之外, 其他站点变异形式均包含方向向 下的趋势变异, 且均为强变异. 藕池口两站点变异幅度远远大于松滋口和太平口站点, 且扣除趋势的新序列 均在 1968 年发生方向向下的跳跃变异.

三口五站年最高洪峰水位的变异情况表现出强烈的关联性(表 2),均在 2004 年发生向下的跳跃变异. 藕池口两站年最高洪峰水位序列扣除了跳跃成分后新序列均在 1968 年还发生了向下的中跳跃变异. 相同 口门的年最高洪峰水位下降幅度相似,各口门的变异程度和幅度从上游至下游逐步递增.

通过上述诊断结果分析可知, 三口五站的年最大洪峰流量序列和年最高水位序列均发生了变异, 且从 变异形式和变异点位置来看, 5 个站点之间存在着一定的成因联系, 因此需要通过分析整个区域的气候条件 和下垫面条件的变化来寻找其变异原因.

\section{3 洞庭湖三口洪峰变异原因分析}

三口洪水变异原因可归结为区域降水和水沙变化影响,其中水沙变化又分为上游来水来沙变化和区域 水沙变化, 尤其是三口站点分流分沙变化. 因此, 主要从以下两个方面进行归因分析: (1) 上游枝城站至三口 站点区域降水的变化; (2) 上游枝城站来流来沙的变化及区间三口站点分流分沙变化. 首先对三口区域的荆 州、南县、岳阳、常德气象站 1956-2014 年极值降雨序列 (年最大 1 日、年最大 3 日、年最大 5 日和年最大 7 日) 进行综合诊断, 结果显示各序列均未发生变异. 因此, 认为区域降水变化不是各站点洪峰流量发生变异 的主要原因,需要对水沙变化及其影响进行分析.

\section{1 水沙变化}

受到环境变化和上游一系列水库建设的影响, 三口上游水沙的输移条件发生了明显变化 ${ }^{[21-22]}$, 加上河 流主支汉之间消长、分流分沙河道淤积萎缩等缓慢现象 ${ }^{[23-24]}$, 形成复杂的江湖关系 ${ }^{[25]}$, 将引起三口各站点年 最大洪峰流量和最高洪峰水位的变化.

江湖关系的调整变化情况通常由分流分沙比来表达 ${ }^{[23]}$. 分流 (沙) 比是指分汉河口中两相邻主、支汉河 道同期径流量 (输沙量) 之比值, 是分析干支流关系的重要指标. 洞庭湖三口在相关研究 ${ }^{[26]}$ 中常常作为一个 整体进行研究, 其分流 (沙) 比是指三口五站的总分流 (沙) 量与上游枝城站来流 (沙) 量之比 ${ }^{[3,26]}$. 三口分流 分沙影响因素的相关研究很多 ${ }^{[25-30]}$, 按照人类活动的标志事件可划分为 5 个阶段 ${ }^{[27]}$ (表 3). 各阶段的人类 活动均使得荆江河段来沙量减少, 河道冲刷下切, 口门进口处与干流河底的高程差加大, 三口分流受到阻 碍, 在一定程度上削弱了荆江三口的分流能力 ${ }^{[28]}$. 下荆江裁弯使得藕池河急剧淤积萎缩, 藕池口分流大幅 下降, 三口分流分沙出现跳跃下降 ${ }^{[29]}$. 三峡水库蓄水运行前, 三口洪道及洞庭湖区以淤积为主, 三口洪道逐 年萎缩, 三口分流能力 ${ }^{[27]}$ 下降. 三峡蓄水运行后, 三口洪道的普遍性冲刷, 口门的冲刷扩展在一定程度上加 强了三口分流能力, 而荆江干流的冲刷下切又削弱了三口分流分沙的能力 ${ }^{[27]}$, 综合来看三口的分流分沙能

表 3 不同阶段三口分流分沙能力变化

Tab.3 Changes of flow/sediment ratio series of the three outlets at five periods

\begin{tabular}{ccccc}
\hline 序号 & 阶段 & 时间 & 平均年分流比 $/ \%$ & 平均年分沙比 $/ \%$ \\
\hline 1 & 下荆江裁弯以前 & $1956-1966$ 年 & 29.30 & 34.98 \\
2 & 下荆江中洲子、上车湾、沙滩子裁弯期 & $1967-1972$ 年 & 23.34 & 27.11 \\
3 & 裁弯后至葛洲坝截流之前 & $1973-1980$ 年 & 18.63 & 21.26 \\
4 & 葛洲坝截流至三峡工程蓄水前 & $1981-2002$ 年 & 15.19 & 17.78 \\
5 & 三峡水库蓄水运行初期 & $2003-2014$ 年 & 11.78 & 20.60 \\
\hline
\end{tabular}


力存在暂时的衰减 ${ }^{[30]}$. 取三口年分流 (沙) 比代表三口的分流 (沙) 能力, 分析各阶段三口分流 (沙) 能力随 时间的变化. 结果显示 (表 3):第 1 3 阶段分流能力变化较为剧烈,第 1 和第 2 阶段变化明显,第 3 阶段进 行了调整 ${ }^{[28]}$; 第 4 和第 5 阶段的分流能力无明显变化,均与第 $1 \sim 3$ 阶段差异明显; 受到裁弯影响, 第 2 阶段 分沙能力急剧下降; 第 5 阶段分沙比上升. 考虑到该阶段荆江三口分沙量中有相当比例的沙量来自于上荆 江河床补给和口门内的冲刷, 若扣除河道补给量, 则分沙比无明显变化 ${ }^{[23]}$, 说明分流能力变化不大.

\section{2 三口站点年最大洪峰流量变异原因综合分析}

枝城站为距离三口站点最近的长江干流站点, 其来水对三口产生重要影响 ${ }^{[31]}$. 对枝城站 (1956-2014 年) 最大洪峰序列进行变异诊断, 采用相对变异幅度描述变异情况, 结果如表 4 所示, 变异情况如图 5 所示.

表 4 枝城站年最大洪峰流量变异诊断结果(1956-2014 年)

Tab.4 Detection results of variabilities in the annual maximum peak flood series measured at the Zhicheng station (1956-2014)

\begin{tabular}{|c|c|c|c|}
\hline \multirow{2}{*}{ 站点 } & \multicolumn{3}{|c|}{ 年最大洪峰流量序列 } \\
\hline & 初步诊断 & 诊断结论 & 变异幅度 \\
\hline 枝城站 & 中变异 & 跳跃变异 $\quad 2004(+) \downarrow$ & $22.3 \%$ \\
\hline
\end{tabular}
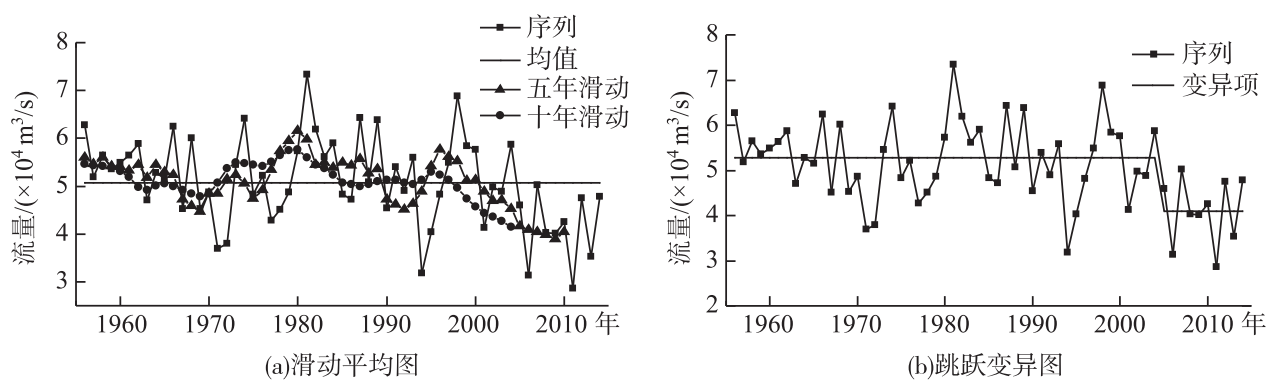

图 5 枝城站年最大洪峰流量变异(1956-2014 年)

Fig.5 Abrupt changes detected in the annual maximum peak flood series measured at the Zhicheng station (1956-2014)

结果显示, 枝城站年最大洪峰流量序列在 2004 年发生向下的跳跃中变异. 时间节点附近上游多座大型 水库修建运行, 例如 2003 年三峡水库开始蓄水运行 ${ }^{[32]}$. 建立枝城站年最大洪峰流量和三峡水库年最大出库 流量的相关关系, 相关系数 $R>0.99$. 假定相关关系不变, 用三峡水库年最大人库数据代替三峡水库年最大出 库流量, 剔除三峡防洪调度影响, “还原” 枝城站的年最大洪峰流量数据. 与得到的还原数据相比, 枝城站年最 大洪峰流量平均下降 $10346 \mathrm{~m}^{3} / \mathrm{s}$, 相对下降幅度为 $19.36 \%$. 下降幅度与枝城站年最大洪峰流量变异幅度相似,

\section{表 5 部分长江上游气象站点极值降雨序列 变异诊断结果 (1960-2014 年)}

Tab.5 Detection results of variabilities in the extreme rainfall series measured at some meteorological stations of the upper reaches of Yangtze River(1960-2014)

\begin{tabular}{ccccc}
\hline 站点 & 年最大 1 日 & 年最大 3 日 & 年最大 5 日 & 年最大 7 日 \\
\hline 重庆站 & $2001 \uparrow$ & 无变异 & 无变异 & 无变异 \\
奉节站 & 无变异 & $1966 \uparrow$ & $1966 \uparrow$ & $1966 \uparrow$ \\
宜宾站 & $1991 \downarrow$ & $1991 \downarrow$ & $1991 \downarrow$ & $1991 \downarrow$ \\
南充站 & 无变异 & 无变异 & 无变异 & $2001 \uparrow$ \\
\hline
\end{tabular}
说明三峡防洪调度对枝城站年最大洪峰变化的影 响巨大. 同时,挑选长江上游降雨对洞庭湖区影响 较大的 10 个代表站点 ${ }^{[33]}$ : 重庆站、彭水站、恩施站、 奉节站、宜昌站、雅安站、乐山站、成都站、宜宾站和 南充站 (图 6), 对站点极值降雨序列 (年最大 1 日、 年最大 3 日、年最大 5 日和年最大 7 日)进行变异分 析(站点序列长度不一, 统一取 1960-2014 年). 部 分站点的极值降雨出现变异 (表 5). 以各站点的最 大 1 日降雨计算最大面平均降雨, 最大面平均降雨 序列无变异, 但各站点最大 1 日降雨发生的时间相 对逐渐分散, 对降雨过程产生影响. 因此, 枝城站的 
来流变化可认为受到了上游气候变化和包括三峡工程在内的上游水库群防洪调度的综合影响 ${ }^{[34]}$.

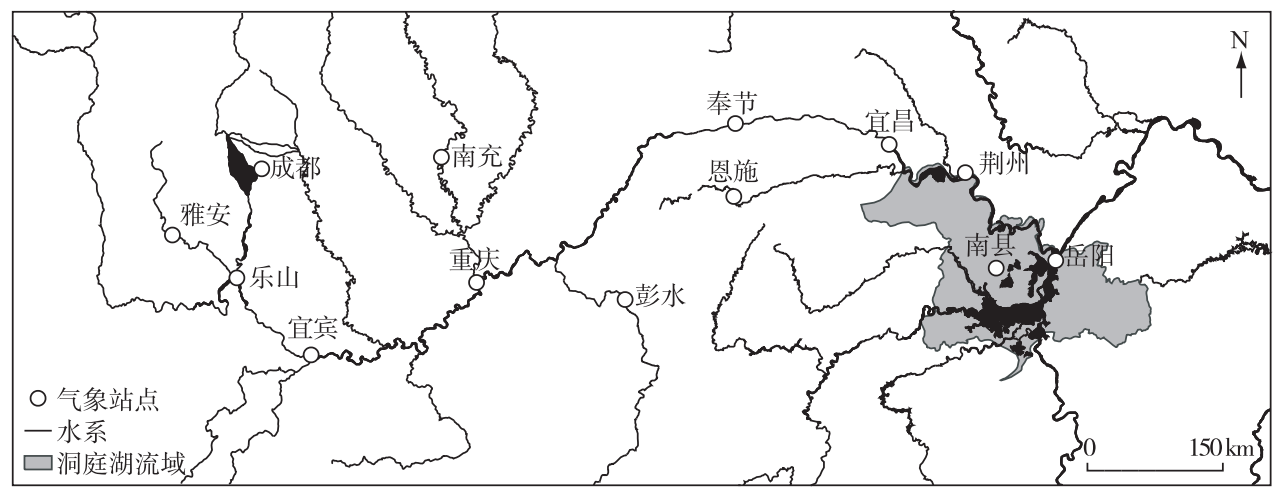

图 6 长江上游气象站点分布

Fig.6 Spatial distribution of ten meteorological stations at upper reaches of the Yangtze River Basin

以 2004 年为节点讨论枝城站径流变化对三口五站洪峰流量变异的影响. 2004 年前枝城站未发生明显 变化, 而三口站点的年最大洪峰流量有明显的衰减, 可能是受到了分流影响, 与分流能力变化有关. 这里取 三口年分流比代表三口的分流能力, 对三口年分流比序列 (1956- 2014 年)进行变异诊断. 变异幅度沿用相 对变异幅度,结果如表 6 所示,变异情况如图 7 所示.

表 6 洞庭湖三口年分流比序列变异诊断结果 (1956-2014 年)

Tab.6 Detection results of variabilities in the flow ratio series measured at the three outlets of Lake Dongting (1956-2014)

\begin{tabular}{cccc}
\hline 序列 & 初步诊断 & 诊断结论 & 变异幅度 \\
\hline 三口年分流比 & 强变异 & 趋势变异 $\downarrow ;$; 跳跃变异 $(1968(+) \downarrow)$ & $70.2 \%($ 年均 $1.2 \%) ; 10.7 \%$ \\
\hline
\end{tabular}

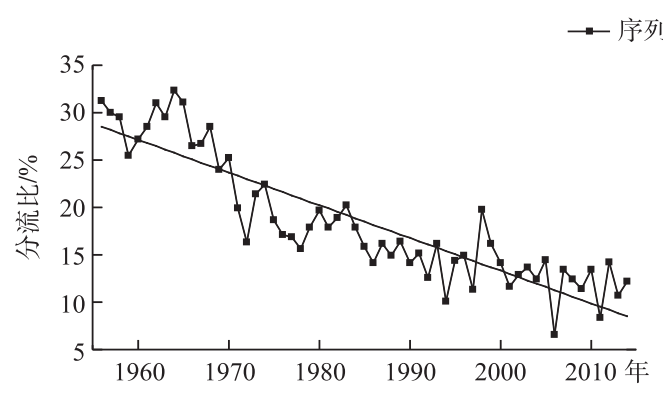

(a)分流比序列跳跃变异图

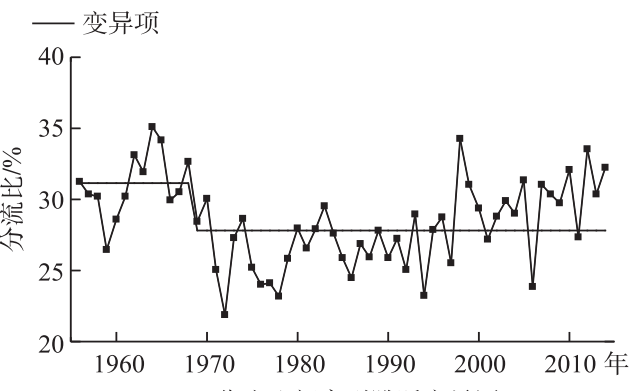

(b)分流比新序列跳跃变异图

图 7 洞庭湖三口年分流比序列变异 (1956-2014 年)

Fig.7 Abrupt changes detected in the annual flow ratio series measured at the three outlets of Lake Dongting (1956-2014)

三口年分流比序列发生向下的趋势变异, 扣除趋势成分后新序列在 1968 年发生向下的跳跃变异, 反映 出分流能力的逐年衰减并在 1968 年出现跳跃下降. 分流比序列的变异形式、变异点位置和变异幅度均与三 口站点年最大洪峰流量序列保持了良好的一致性. 为进一步验证两者的相关性, 计算分流比序列与各站点 洪峰年最大流量序列的相关系数. 结果 (表 7) 显示, 年分流比序列除了和新江口站的相关系数较低外, 与其 余站点的相关系数均超过 0.8 , 通过显著水平 0.05 条件下的显著性假设. 因此, 可用分流比变化对除新江口 站外各站点的年最大洪峰流量序列的趋势变异进行解释. 有资料 ${ }^{[35]}$ 表明在三口洪道分流持续大幅递减中, 
松滋口相比其他口门分流衰减幅度最小,与整体的分流变化差异较大, 印证了上述分析. 新江口站为离枝城 站最近的站点, 受来流影响大, 新江口站年最大洪峰流量 2000 年发生变异, 相比枝城站时间上略有提前, 变 异形式和方向一致, 变异幅度相似. 结合上述松滋河分流衰减分析 ${ }^{[35]}$, 认为新江口站流量受到枝城站来流 变化与松滋河分流衰减的叠加影响, 在 2000 年提前发生了跳跃变异. 康家岗站和管家铺站年最大洪峰流量 序列和分流比新序列均在 1968 年发生了方向向下的跳跃变异, 认为受到 1967-1972 年的下荆江中洲子、上 车湾和沙滩子裁弯的影响. 裁弯使得河道顺直, 口门分流能力降低, 分流量减少. 而藕池口口门紧邻 3 个裁 弯河段的上端, 受到影响最为明显 ${ }^{[26]}$. 对下荆江裁弯前后三口五站的流量变化情况进行对比分析, 也验证 了藕池口两站点变化最为剧烈 (表 8 ).

表 7 洞庭湖三口分流比序列和各站点年最大洪峰流量序列的相关关系

Tab.7 Correlation efficient between annual flow ratio series and annual maximum peak flood series measured at five hydrological stations in the three outlets of Lake Dongting

\begin{tabular}{cccccc}
\hline 站点 & 新江口站 & 沙道观站 & 弥陀寺站 & 康家岗站 & 管家铺站 \\
\hline 相关系数 & 0.40 & 0.84 & 0.92 & 0.81 & 0.95 \\
\hline
\end{tabular}

表 8 下荆江裁弯前后三口五站流量变化

Tab.8 Changes in flooding peak flow before and after cut-offs at five stations in the lower reach of the Jingjiang River Basin

\begin{tabular}{|c|c|c|c|c|c|}
\hline \multirow[b]{2}{*}{ 站点 } & \multicolumn{3}{|c|}{ 平均年最大洪峰流量/ $\left(\mathrm{m}^{3} / \mathrm{s}\right)$} & \multicolumn{2}{|c|}{ 相对变化 } \\
\hline & $\begin{array}{c}\text { 裁弯前 } \\
(1956-1966 \text { 年) }\end{array}$ & $\begin{array}{c}\text { 裁弯期 } \\
(1967-1972 \text { 年) } \\
\end{array}$ & $\begin{array}{c}\text { 裁弯后 } \\
(1973-1980 \text { 年) }\end{array}$ & 裁弯前与裁弯期 & 裁弯期与裁弯后 \\
\hline 新江口站 & 4895.5 & 4358.3 & 4702.5 & $-10.97 \%$ & $7.90 \%$ \\
\hline 沙道观站 & 2922.7 & 2153.3 & 2217.5 & $-26.32 \%$ & $2.98 \%$ \\
\hline 弥陀寺站 & 2833.6 & 2366.7 & 2298.8 & $-16.48 \%$ & $-2.87 \%$ \\
\hline 康家岗站 & 1740.9 & 836.5 & 540.9 & $-51.95 \%$ & $-35.34 \%$ \\
\hline 管家铺站 & 10217.3 & 6966.7 & 5702.5 & $-31.81 \%$ & $-18.15 \%$ \\
\hline
\end{tabular}

2004 年枝城站的年最大洪峰流量出现向下的跳跃变异, 这将直接影响洞庭湖三口站点的年最大洪峰流 量, 此时各站点洪峰流量的趋势变化除了与分流能力变化有关外, 还与枝城站来流变化有关. 记三口平均年 最大洪峰总流量为三口五站各年的年最大洪峰总流量的算术平均值, 对比 2005-2014 年和 1995-2004 年 三口平均年最大洪峰总流量和分流能力. 三口平均年最大洪峰总流量相比下降 $28.0 \%$, 远大于分流比的变 化量 10.8\%. 其中分流比年均递减 1.08\%,与 1956- 2014 年整体年均递减 $1.2 \%$ 相近, 平均年最大洪峰流量 年均递减 2.8\%, 远大于 1956-2014 年三口洪峰总流量整体年均递减 1.1\%. 认为枝城站来流变化对三口五 站年最大洪峰流量产生了很大影响.

综上,2004 年枝城站的年最大洪峰流量发生变异前除新江口站外,各站点年最大洪峰流量的向下趋势 变异和跳跃变异可以通过分流能力变化来进行解释, 新江口站年最大洪峰流量向下的跳跃变异受枝城站年 最大洪峰流量和三口洪道分流的叠加影响, 发生时间略早于枝城站来流变化. 2004 年枝城站的年最大洪峰 流量发生变异后, 分流能力变化和来流变化均对各站点洪峰流量减小产生影响, 来流变化使得洪峰流量减 小加剧.

\section{3 三口站点年最高洪峰水位变异原因综合分析}

由于缺乏洪峰时的瞬时输沙值观测值, 且上游输沙变化对洪峰水位影响主要体现在总输沙量对区域冲 淤变化等的影响. 因此, 对枝城站 (1956-2014 年) 年输沙量序列进行变异诊断来分析上游来沙变化, 结果 如表 9 所示, 变异情况如图 8 所示. 序列在 2001 年发生跳跃向下的巨变异, 即输沙量剧减. 剔除跳跃变异成 分后, 新序列在 1985 年再次出现跳跃向下的变异, 变异幅度较小. 变异的时间和物理机理与三峡和葛洲坝 工程建设运行相吻合, 即水电站的建设运行将拦蓄泥沙, 使得下游站点的年输沙量发生跳跃性下降. 对三口 
年分沙比进行变异诊断, 结果显示分沙比在 1970 年发生方向向下的跳跃变异, 变异幅度为 $42.8 \%$, 即分沙能 力在 1970 年出现剧减,受到下荆江裁弯影响.

$$
\text { 表 } 9 \text { 枝城站年输沙量变异诊断结果( 1956-2014 年) }
$$

Tab.9 Detection results of variabilities in the annual sediment series measured at the Zhicheng station (1956-2014)

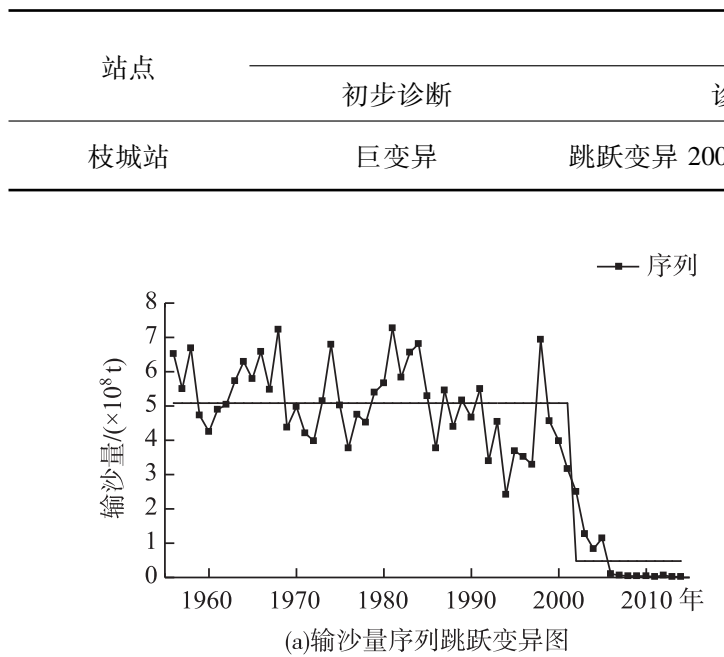

年输沙量序列

诊断结论变异幅度

\begin{tabular}{|c|c|c|c|}
\hline 枝城站 & 巨变异 & 跳跃变异 2001(+) $\downarrow ; 1985(+) \downarrow$ & $90.68 \% ; 15.45 \%$ \\
\hline
\end{tabular}

图 8 枝城站年输沙序列变异(1956-2014 年)

Fig.8 Abrupt changes detected in the annual sediment series measured at the Zhicheng station (1956-2014)

三口五站的年最高洪峰水位均在 2004 年发生方向向下的跳跃变异, 跳跃变异的幅度较为一致. 时间上 与三峡蓄水运用相近,一些研究认为该时段的水位变化受到三峡拦蓄泥沙的影响 ${ }^{[6]}$. 通常认为上游来沙量 的减少将导致下游河道的冲刷 ${ }^{[36]}$. 枝城站年输沙量在 2001 年出现剧减,而分沙比在此时未发生大的变化, 势必对三口的冲淤变化产生影响. 对三口河道不同时段冲淤量进行统计 ${ }^{[9]}$ (表 10 ), 可以发现三口河道由淤 积状态转为冲刷状态 ${ }^{[37]}$. 三口河道冲刷将增加河道槽蓄量, 河道行洪能力将得到增强, 在通过相同流量时 水位会出现下降, 与蓄水后各站点的年最大洪峰水位下降情况高度一致. 因此, 上游来沙量的减少引起的河 道冲淤变化是三口五站的年最高洪峰水位发生方向向下变异的原因之一.

表 10 三口河道不同时段冲淤量 ${ }^{[9]}$

Tab.10 Amounts of scouring and silting sand at different time periods in three rivers

\begin{tabular}{ccrrrr}
\hline 项目 & 时段 & 松滋河 & 虎渡河 & 藕池河 & 三口总计 \\
\hline 总冲淤量 $/\left(\times 10^{8} \mathrm{~m}^{3}\right)$ & $1993-2003$ 年 & 0.0243 & 0.1317 & 0.3106 & 0.4676 \\
& $2004-2014$ 年 & -0.4258 & -0.1493 & -0.1769 & -0.7520 \\
\hline
\end{tabular}

三口站点洪峰水位变化还受到洪峰流量变化和洞庭湖顶托作用的影响. 各站点的洪峰流量均出现下降. 三峡水库蓄水后, 荆江的冲刷下切及洞庭湖的淤积减少在一定程度上减弱了荆江与洞庭湖之间的相互顶托 作用 ${ }^{[28]}$. 流量减小和顶托作用的减小均对水位的下降有促进作用.

有研究 ${ }^{[9,38]}$ 认为除了河道冲淤、流量和顶托作用外, 影响三口站点洪水位变化的因素还常常包括河床纵 剖面变化和水面比降变化. 其中, 陈佮煌等 ${ }^{[9]}$ 分析了三口洪道进口段深泓纵剖面变化, 并得出了三口洪道口 门段深泓纵剖面总体变化不大, 对蓄水后三口洪道洪水位变化趋势无明显影响的结论. 建立三口五站 2004 年前后洪峰流量和洪峰水位相关关系, 可以发现 2004 年后各站的水位和流量均低于平均状态. 剔除 2006 年 极端点距的影响后同流量下对应的水位略有下降, 总体比较稳定, 对洪峰水位下降略有促进作用. 总体来看 


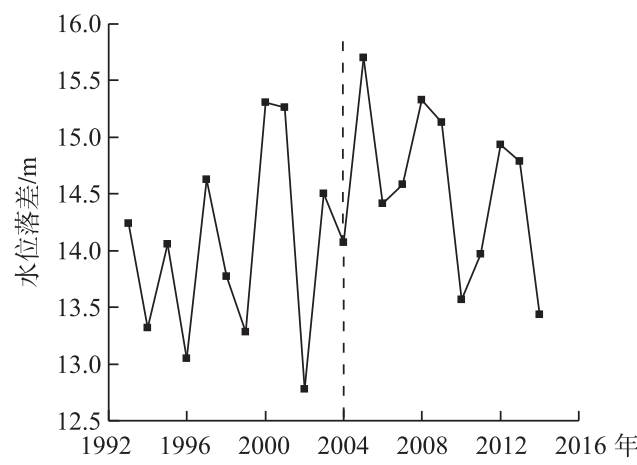

图 9 洞庭湖三口历年水位落差变化

Fig.9 Difference of water levels between the upper and lower reaches in the three outlets of Lake Dongting

纵剖面总体变化不大, 在此不再赘述. 相关研究 ${ }^{[6]}$ 认为: 受到三峡工程影响,枝城站和洞庭湖出口城陵矶站的水 位落差发生变化. 而两站水位落差变化会影响三口洪水 位的水面比降变化, 进而影响洪水位变化; 当上下游落 差增大时,洪水位下降. 计算 1993-2014 年的 7、8 月份 枝城站和洞庭湖出口城陵矶站平均落差, 分析 19932003 年和 2004-2014 年平均水位落差变化 (图 9), 以 2004 年为界, 可以发现 2004 年后水位落差有抬升, 1993-2003 年水位落差的均值为 $14.02 \mathrm{~m}$, 而 20042014 年变为 $14.55 \mathrm{~m}$, 增加了 $0.53 \mathrm{~m}$, 枝城站和洞庭湖出 口城陵矶站上下落差整体增大, 将对年最高洪峰水位下 降起到促进作用.

上文分析了康家岗站和管家铺站的年最大洪峰流 量受到裁弯的影响出现跳跃下降. 裁弯使得河道顺直, 分流量减少. 而河道顺直使得流程减小和水位比降增大 导致河床刷深及同流量水位下降 ${ }^{[39]}$. 即受到裁弯影响, 年最大洪峰流量迅速减小且同流量水位下降. 因此, 流量减小和河床冲刷共同导致了两站点年最高洪峰水位发生跳跃变异.

综上,2004 年各站点年最高洪峰水位变异受到上游来沙量减少引起的河道冲刷、洪峰流量下降、顶托作 用减弱和洪道上下游落差变动影响. 1968 年康家岗站和管家铺站两站点在年最高洪峰水位发生跳跃向下的 变异受到裁弯影响,流量减小和河床冲刷共同导致年最高洪峰水位的变异.

\section{4 结论与展望}

本文主要利用水文变异诊断系统, 对洞庭湖三口的 5 个水文站点年最大洪峰流量序列和年最高洪峰水 位序列进行变异诊断,并归纳其变异特征和物理成因. 研究结果表明:

1) 三口各站点年最大洪峰流量主要呈现向下的趋势变异. 新江口站在 2000 年发生向下的跳跃弱变异; 其他站点均为向下的强趋势变异. 藕池口两站点年最大洪峰流量序列趋势变异幅度在三口中远大于松滋口 和太平口, 扣除趋势成分后新序列均在 1968 年发生方向向下的跳跃变异.

2)三口五站年最高洪峰水位的变异情况表现出强烈的关联, 均在 2004 年发生向下的跳跃变异. 藕池口 两站序列扣除了跳跃成分后新序列均在 1968 年还发生了向下的中跳跃变异.

3) 归因分析结果认为, 在 2004 年上游枝城站的年最大洪峰流量变异之前, 三口各站点的年最大洪峰流 量的趋势变异与分流能力变化有关. 2004 年之后与分流能力和上游枝城站的来流变化均有关, 来流变化使 得三口洪峰流量减小加剧.

4) 三口各站点年最高洪峰水位均在 2004 年发生向下的跳跃变异, 主要与三峡工程运行、河道冲刷、流 量减小、顶托作用减弱和洪道上下游落差增大有关. 受到裁弯影响, 流量减小和河床冲刷综合导致了藕池口 两站点水位在 1968 年发生跳跃向下的变异.

此外, 考虑到上游枝城站来水和三口分流分沙均受到众多因素的影响, 其物理机制等还需要进一步研 究, 以期得到更全面和准确的认识.

\section{5 参考文献}

[ 1 ] Peng YM, Duan WZ, Chen YH. Change of the three outlets in Jingjiang River and the regulation scheme. Journal of Sediment Research, 2007，(6) : 59-65. [彭玉明, 段文忠, 陈永华. 荆江三口变化及治理设想. 泥沙研究, 2007, (6) : 59-65.]

[ 2 ] Li JB, Qin JX, Wang KL et al. The response of environment system changes of Dongting Lake to hydrological situation. Acta Geographica Sinica, 2004, 59(2) : 239-248. [李景保, 秦建新, 王克林等. 洞庭湖环境系统变化对水文情势的响 应. 地理学报, 2004, 59(2) : 239-248.] 
[ 3 ] Cao WH, Mao JX. Impacts of Three Georges Reservoir's operation on Jingiiang River and outflow of the three outlets. Water Resources and Hydropower Engineering, 2015, 46(6) : 67-71. [曹文洪, 毛继新. 三峡水库运用对荆江河道及三口分 流影响研究. 水利水电技术, $2015,46(6): 67-71$.

[ 4 ] Huang Y, Yao SM, Lu JY. Impact of TGP operation on the hydrologic regime in the downstream main channel of the dam. Journal of Yangtze River Scientific Research Institute, 2011, 28(7): 76-81. [黄悦, 姚仕明, 卢金友. 三峡水库运用对 坝下游干流河道水文情势的影响研究. 长江科学院院报, 2011, 28(7): 76-81.]

[ 5 ] Li JB, He X, Yang B et al. Temporal evolution of dried up days and the influencing mechanisms at three outlets along Jingjiang in the Middle Reach of Yangtze River. Journal of Natural Resources, 2016, 31 (10): 1713-1725. DOI: 10. 11849/zrzyxb.20151021. [李景保, 何霞, 杨波等. 长江中游荆南三口断流时间演变特征及其影响机制. 自然资源 学报, 2016, 31(10): 1713-1725.]

[ 6 ] Mao BP, Mei JY, Zhang JH et al. Analysis of water and sediments transportation of three river-outlets flood channels from Yangtze River to Dongting Lake. Yangtze River, 2010, 41(2): 38-42. [毛北平, 梅军亚, 张金辉等. 洞庭湖三口洪道 水沙输移变化分析. 人民长江, 2010, 41(2): 38-42.]

[ 7 ] Li ZZ, Xie YB, Xu DM. Runoff-sediment variation and its effect on the Dongting Lake. Hydrology, 2011, 31(1) : 45-53. [李正最, 谢悦波, 徐冬梅. 洞庭湖水沙变化分析及影响初探. 水文, 2011, 31(1): 45-53.]

[ 8 ] Zheng WY. Variations and effects on the flow and sediment diversion in the three outlets along Jingiang River [Dissertation]. Wuhan: Yangtze River Scientific Research Institute, 2005. [郑文燕. 荆江三口分流分沙变化及其影响研究 [学 位论文]. 武汉: 长江科学院, 2005.]

[ 9 ] Chen JH, Peng YM, Yang J et al. Analysis on the change of the flood level of the three flood channels in the Three Gorges Reservoir since the water storage operation of the Three Gorges Reservoir. In: China Water Technology Information Center ed. National River and Lake Governance and Ecological Civilization Development Forum 2015, 2015: 115-119. [ 陈俭煌, 彭玉明, 杨军等. 三峡水库蓄水运行以来荆江三口洪道洪水位变化分析. 见: 中国水利技术信息中心编. 2015 全 国河湖治理与生态文明发展论坛文集，2015: 115-119.]

[10] Gan MH, Liu KB, Yang DW et al. Analysis on the flood control, water supply and water environment protection in the region of Dongting Lake along Yangtze River. Journal of Hydroelectric Engineering, 2011, 30(5) : 5-9. [甘明辉, 刘卡波, 杨大文等. 洞庭湖四口河系防洪、水资源与水环境研究. 水力发电学报, 2011, 30(5): 5-9.]

[11] Xu HJ, Xu D, Ning L et al. Impacts analysis of major human activities on flow and sediment diversion from four outlets of Dongting Lake. China Rural Water and Hydropower, 2014, (9) : 127-130. [徐慧娟, 许多, 宁否等. 重大人类活动对 洞庭湖四口水系洪水特性的影响分析. 中国农村水利水电, 2014, (9) : 127-130.]

[12] Xie P, Chen GC, Lei HF et al. Hydrological alteration diagnosis system. Journal of Hydroelectric Engineering, 2010,29 (1)：85-91. [谢平, 陈广才, 雷红富等. 水文变异诊断系统. 水力发电学报, 2010, 29(1) : 85-91.]

[13] Zivot E. Further evidence on the great crash, the oil-price shock, and the unit-root hypothesis. Journal of Business and Economic Statistics, 2002, 10(1) : 251-270.

[14] Robin LL, David HP. Multiple trend breaks and the unit-root hypothesis. Review of Economics and Statistics, 1997,79 (2) : 212-218.

[15] Xie P, Chen GC, Xia J. Hydrological frequency calculation principle of inconsistent annual runoff series under Changing environments. Engineering Journal of Wuhan University, 2005, 38(6): 6-10. [谢平, 陈广才, 夏军. 变化环境下非一 致性年径流序列的水文频率计算原理. 武汉大学学报: 工学版, 2005, 38(6): 6-10.]

[16] Worrall TP, Dunbar MJ, Extence CA. The identification of hydrological indices for the characterization of macroinvertebrate community response to flow regime variability. Hydrological Sciences Journal/journal Des Sciences Hydrologiques, $2014, \mathbf{5 9}$ (3/4) : 645-658.

[17] Machiwal D, Jha MK eds. Hydrologic time series analysis: Theory and practice. Dordrecht: Springer Netherlands, 2012: 181-183.

[18] Xie P, Tang YS, Li BB et al. Hydrological trend variation classification method based on correlation coefficient. Journal of Basic Science and Engineering, 2014, 22 (6) : 1089-1097. [谢平, 唐亚松, 李彬彬等. 基于相关系数的水文趋势变异 分级方法. 应用基础与工程科学学报, 2014, 22(6): 1089-1097.]

[19] Hendry D, Mizon G. Forecasting in the presence of structural breaks and policy regime shifts. Economics Papers, 2005 : 480-502.

[20] Luan HD. Unit root test allowing for structural breaks: A literature review. The Journal of Quantitative \& Technical Economics, 2007, 24(3) : 152-160. [栾惠德. 带有结构突变的单位根检验一文献综述. 数量经济技术经济研究, $2007,24(3): 152-160$.

[21] Qu G, Shen J, Gong YG. Analyze on flow and sediment trend of upper reaches of Yangzi River and its affects. Water Con- 
servancy Science and Technology and Economy, 2005, 11(12): 752-756. [渠庚, 沈俊, 巩艳国. 长江上游地区来水来 沙变化趋势及其影响研究. 水利科技与经济, 2005, 11(12) : 752-756.]

[22] Wang YG, Hu CH, Liu Q et al. Study on variations of runoff and sediment load in the Upper Yangtze River and main influence factors. Journal of Sediment Research, 2016, (1) : 1-8. [王延贵, 胡春宏, 刘茜等. 长江上游水沙特性变化与 人类活动的影响. 泥沙研究, 2016, (1) : 1-8.]

[23] Guo XH, Li YT, Liu Y. Analysis of flow and sediment diversion at three outlets along Jingiang River. Journal of Sediment Research, 2014, (1) : 53-60. [ 郭小虎, 李义天, 刘亚. 近期荆江三口分流分沙比变化特性分析. 泥沙研究, 2014, (1) : 53-60.]

[24] Yu XM, Tan GM. Research on diversion model of discharge and sediment with the erosion and deposition of river. Engineering Journal of Wuhan University, 2005, 38(1): 44-48. [余新明, 谈广鸣. 河道冲淤变化对分流分沙比的影响. 武汉大学学报工学版, 2005, 38(1): 44-48.]

[25] Zhong ZY, Hu WZ. On relation of river and lake. Yangtze River, 2008, 39(1): 20-22, 30. [ 仲志余, 胡维忠. 试论江湖 关系. 人民长江, $2008,39(1): 20-22,30]$

[26] Xu QX, Hu GY, Yuan J. Research on the flow and sediment diversion in the three outlets along Jingiiang River in recent 50 years. Journal of Sediment Research, 2009, (5): 1-8. [许全喜, 胡功宇, 袁晶. 近 50 年来荆江三口分流分沙变化 研究. 泥沙研究, 2009, (5) : 1-8.]

[27] Qin K, Peng YM, Chen JH. Analysis on change of flow diversion capacity of three channels of Jingiiang River. Yangtze River, 2015, 46(18) : 34-38. [秦凯, 彭玉明, 陈俭煌. 荆江三口分流能力变化分析. 人民长江, 2015, 46(18): 3438.]

[28] Zhu LL, Chen JC, Yuan J et al. Study on variation trends of flow diversion from Jingjiang River to Dongting Lake. Journal of Hydroelectric Engineering, 2015, 34(2): 103-111. [ 朱玲玲, 陈剑池, 袁晶等. 基于时段控制因子的荆江三口分 流变化趋势研究. 水力发电学报, 2015, 34(2): 103-111.]

[29] Guo XH. Runoff and sediment diversion of Songzikou. Journal of Basic Science and Engineering, 2014, 22(3): 457-468. [ 郭小虎, 李义天, 朱勇辉等. 松滋口口门分流分沙比变化特性. 应用基础与工程科学学报, 2014, 22(3): 457-468.]

[30] Lu JY, Zhu YH. Issues on evolution and regulation of Yangtze River and lakes downstream of TGP. Journal of Yangtze River Scientific Research Institute, 2014, 31(2) : 98-107. [卢金友, 朱勇辉. 三峡水库下游江湖演变与治理若干问题探 讨. 长江科学院院报. $2014,31(2)$ : 98-107.]

[31] Huo YF. The change of River-Lake relations and the effect to flood control of dredging up [Dissertation]. Nanjing: HoHai University, 2005. [霍勇峰. 长江中游江湖关系变化及疏浚对防洪的影响 [学位论文]. 南京: 河海大学, 2005.]

[32] Sendiment Panel of the Three Gorges Project ed. Summary of field data for sedimentation in the Three Gorges Project during the initial filling period: 2003-2006. Beijing: China Water \& Power Press, 2008: 5-6. [三峡工程泥沙专家组. 长江三 峡工程围堰蓄水期 (2003-2006 年) 水文泥沙观测简要成果. 北京: 中国水利水电出版社, 2008: 5-6.]

[33] Liu XQ, Mao DH. Forecast model of flood in the Dongting Lake region. Journal of Natural Disasters, 1993, 2(3) : 43-46. DOI: 10.13577/j.jnd.1993.0306. [刘晓清, 毛德华. 洞庭湖区洪涝灾害的预报模式. 自然灾害学报, 1993, 2(3): 43-46. ]

[34] Lai X, Liang Q, Jiang J et al. Impoundment effects of the Three-Gorges-Dam on flow regimes in two China's largest freshwater lakes. Water Resources Management, 2014, 28(14) : 5111-5124. DOI: 10.1038/460173b.

[35] Huang HL, Xiao HC. Water diversion evolution tendency of the Songzi river. Yangtze River, 2007, 38(6): 43-46. [黄火 林, 肖虎程. 松滋河分流演变发展趋势. 人民长江, 2007, 38(6) : 43-46.]

[36] Hu CH. Development and practice of the operation mode of “Storing Clear Water and Discharging Muddy Flow” in sediment-laden rivers in China. Journal of Hydraulic Engineering, 2016, 47(3): 283-291. [胡春宏. 我国多沙河流水库 “蓄清排浑”运用方式的发展与实践. 水利学报, 2016, 47(3) : 283-291.]

[37] Xu QX, Zhu LL, Yuan J. Research on water-sediment variation and deposition-erosion in middle and lower Yangtze River. Yangtze River, 2013, 44(23): 16-21. [许全喜, 朱玲玲, 袁晶. 长江中下游水沙与河床冲淤变化特性研究. 人民长 江, 2013, 44(23): 16-21.]

[38] Yu MH, Duan WZ, Yu WQ. Analysis of river bed change of Yangtze River and flood level variation. Engineering Journal of Wuhan University, 2005, 38(3) : 1-5. [余明辉, 段文忠, 余蔚卿. 长江中下游河床冲淤与洪水位变化. 武汉大学 学报工学版, 2005, 38(3): 1-5.]

[39] Lu JY, Huang Y, Gong P. Scouring and silting variation in middle and lower channel of the Yangtze river after TGP operation. Yangtze River, 2006, 37(9) : 55-57, 87. [卢金友, 黄悦, 宫平. 三峡工程运用后长江中下游冲淤变化. 人民长 江, 2006, 37(9): 55-57, 87.] 